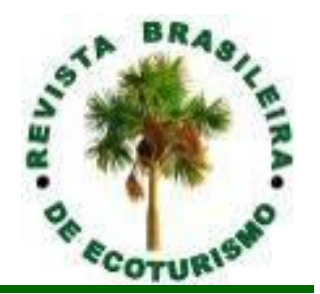

\title{
Trilhas Interpretativas para o Uso Público em Parques: Desafios para a Educação Ambiental
}

\section{Interpretive Trails for Public Use in Parks: Challenges for Environmental Education}

\author{
Priscila Gonçalves Costa, Douglas de Souza Pimentel, Alba Valéria Santos Simon, \\ Amaro Rodrigo Correia
}

RESUMO: A Educação Ambiental (EA) é uma dimensão do uso público em áreas protegidas prevista para todas as categorias de manejo do Sistema Nacional de Unidades de Conservação (SNUC). Nesse contexto, as Unidades de Conservação (UC) necessitam ganhar significado para a sociedade e podem servir como locus das ações de consolidação da Política de Educação Ambiental (PEA). Essas têm potencial para reaproximar as pessoas dos ambientes naturais pela afetividade e reflexão e permitir uma visão prática e crítica das relações da sociedade com a natureza. Além disso, a EA, enquanto uma prática social pode contribuir para fomentar a integração participativa e democrática nas decisões sobre a sua gestão. O presente trabalho visa à elaboração de Trilhas Interpretativas ( $\mathrm{TI}$ ) como proposta pedagógica e ferramenta de EA, baseadas nas atividades de sensibilização e Interpretação Ambiental. Através de diversas etapas e baseado em metodologia de pesquisa social, o trabalho analisa a elaboração de diferentes trilhas interpretativas feitas por alunos do Ensino Médio do CIEP-449 Governador Leonel de Moura Brizola Brasil-França, localizado em Niterói, RJ, em parceria com o Grupo de Estudos Interdisciplinares do Ambiente, da Universidade do Estado do Rio de Janeiro (UERJ/FFP). No primeiro momento da pesquisa, as trilhas foram divididas em diferentes temas, obedecendo a proposta pedagógica e a base curricular da escola. A partir do segundo momento, o trabalho segue com a discussão e elaboração de uma nova trilha interpretativa, baseada nas trilhas feitas pelos alunos. A nova TI é do tipo guiada e tem uma abordagem pedagógica que busca a interdisciplinaridade. A área de estudo da pesquisa é a trilha do Costão de Itacoatiara, inserida no Parque Estadual da Serra da Tiririca, em bairro vizinho ao CIEP. O contexto social da turma, as diferentes vertentes da Educação Ambiental e os conflitos que envolvem as Unidades de Conservação foram discussões centrais neste trabalho, além da abordagem dos conceitos de interpretação ambiental e trilhas interpretativas. Com o resultado, pode-se analisar o uso das TI no planejamento e gestão do uso público nos parques e verificar sua eficácia com estratégia de conservação e como proposta pedagógica, a partir da sensibilização e construção de um pensamento crítico sobre questões socioambientais, minimização de impactos negativos da visitação e envolvimento dos alunos na conservação da biodiversidade, além de os auxiliarem no processo de ensino-aprendizagem.

PALAVRAS CHAVE: Parque Estadual da Serra da Tiririca; Educação Ambiental Crítica; Trilhas Interpretativas; Projeto Político Pedagógico. 
ABSTRACT: Environmental Education is a dimension of public use in protected areas foreseen for all management categories of the National System of Protected Areas. In this context, Conservation Units need to gain meaning for society and can serve as a locus of actions for the consolidation of Environmental Education Policy. These have the potential to reconnect people from the natural environment with affectivity and reflection and to allow a practical and critical view of society's relations with nature. In addition, Environmental Education, while a social practice can contribute to foster participatory and democratic integration in decisions about its management. The present work aims at the elaboration of Interpretive Trails as pedagogical proposal and Environmental Education tool, based on the activities of environmental awareness and interpretation. Through several stages and based on social research methodology, the work analyzes the elaboration of different interpretative trails made by CIEP-449 Governador Leonel de Moura Brizola BrazilFrança high school students, located in Niterói, RJ, in partnership with the Environmental Interdisciplinary Studies Group, of the Rio de Janeiro University. At the first moment of the research, the tracks were divided into different themes, obeying the pedagogical proposal and the curricular base of the school. From the second moment, the work follows with the discussion and elaboration of a new interpretative trail, based on the trails made by the students. The new IT is of the guided type and has a pedagogical approach that seeks interdisciplinarity. The area of study of the research is the trail of Costão de Itacoatiara, inserted in the State Park of Serra da Tiririca, in a neighborhood next to the CIEP. The social context of the class, the different aspects of environmental education and the conflicts involving the Protected Areas were central discussions in this work, as well as the approach of the concepts of environmental interpretation and interpretive trails. With the result, it is possible to analyze the use of interpretive trails in the planning and management of public use in the parks and to verify its effectiveness with conservation strategy and as a pedagogical proposal, based on the sensitization and construction of a critical thinking about socio-environmental issues, minimization of negative impacts of visitation and involvement of students in biodiversity conservation, as well as helping them in the teaching-learning process.

KEYWORDS: Serra da Tiririca State Park; Critical Environmental Education; Interpretive Trails; Pedagogical Political Project.

\section{Introdução}

O crescimento das populações urbanas provocou um aumento na busca por áreas naturais para recreação, relaxamento, contemplação e turismo. Em consonância, emergiu a discussão sobre a necessidade de proteção dos remanescentes de natureza juntamente com políticas públicas para a criação de Áreas Protegidas (APs).

As Unidades de Conservação (UC) representam um tipo de AP brasileira e estão divididas legalmente, por categorias de manejo, sendo elas de Uso Sustentável e de Proteção Integral. No caso dos parques, como UC de Proteção Integral, o foco principal é a conservação dos ecossistemas, mas há também a previsão de desenvolvimento de diferentes atividades de uso público. $O$ art. 11 da 
Lei 9.985/2000, que estabelece o Sistema Nacional de Unidades de Conservação, considera que os parques:

[...] têm como objetivo básico a preservação de ecossistemas naturais de grande relevância ecológica e beleza cênica, possibilitando a realização de pesquisas científicas e 0 desenvolvimento de atividades de educação e interpretação ambiental, de recreação em contato com a natureza e de turismo ecológico.

Prevista em lei, a Educação Ambiental (EA) surgiu no contexto de emergência de uma crise ambiental reconhecida nas décadas finais do século XX e estruturouse como fruto de uma demanda para que o ser humano adotasse uma visão de mundo e uma prática social capazes de minimizar os impactos ambientais então prevalecentes (Lima, 2011). A partir da década de 1970, a EA tornou-se tema de debate na vida social mundial, sendo defendida e, segundo Lima (2011), dando oportunidade para reflexão e definição de seus objetivos e significados. Diante da crise, ainda segundo o autor, a Educação Ambiental começou a ser apontada como um dos instrumentos relevantes na busca de respostas para solucioná-la.

A EA tem a intencionalidade de dar aos sujeitos condições de desenvolver uma atuação transformadora na sociedade. Segundo o Programa Nacional de Educação Ambiental, "a Educação Ambiental deve se pautar por uma abordagem sistêmica, capaz de integrar os múltiplos aspectos da problemática ambiental contemporânea" (ProNEA, 2014, p. 24). O documento ainda destaca a que "a abordagem deve reconhecer $o$ conjunto das inter-relações $e$ as múltiplas determinações dinâmicas entre os âmbitos naturais, culturais, históricos, sociais, econômicos e políticos" (ProNEA, 2014, p. 24).

A discussão sobre a diferenciação do campo da Educação Ambiental no Brasil é construída contrapondo-as com a ferramenta de Trilhas Interpretativas (TI). Seguindo esta lógica, o trabalho também apresenta o conceito de Interpretação Ambiental (IA), utilizada explicitamente para propósitos ambientais e de conservação, traduzindo a linguagem técnica de uma ciência natural em ideias que as pessoas em geral - que não são técnicas - consigam entender. $O$ foco da interpretação não é a instrução, mas sim a provocação, que a interpretação deve representar um todo e não uma parte, e deve ser direcionada para todos os tipos de pessoas (HAM, 1992 apud Carvalho e Moreira, 2017).

Neste sentido, o presente trabalho tem como objetivo apresentar os procedimentos para estruturação de Trilhas Interpretativas na trilha do Costão de Itacoatiara, pertencente ao Parque Estadual da Serra da Tiririca (PESET), através de uma pesquisa participativa com alunos de Ensino Médio do CIEP-449 Governador Leonel de Moura Brizola Brasil-França.

A Unidade de Conservação escolhida está situada entre os Municípios de Niterói e Maricá, no Estado do Rio de Janeiro, Brasil e apresenta crescente pressão humana no entorno, intensa especulação imobiliária e vem despertando interesse para novos empreendimentos. Interessante notar que o PESET se estabeleceu como o primeiro parque criado a partir de movimentos sociais, em 1991 (SIMON, 2003; VALLEJO, 2005; PIMENTEL, 2008) e apesar de altos e baixos ainda há 
mobilização da sociedade em prol da conservação do Parque. Sua existência tão próxima aos centros urbanos, portanto, Ihe confere um atributo de disseminador de ideias, conceitos e políticas ambientais para a sociedade (INEA, 2015).

O outro parceiro institucional importante do trabalho é o Ciep 449 Leonel de Moura Brizola, também conhecido como Instituto Intercultural Brasil-França. A escola pública está vinculada à Secretaria de Estado de Educação do Rio de Janeiro (SEEDUC/RJ). Localizado no bairro de Charitas, em Niterói, o estabelecimento de ensino surgiu de uma parceria entre a Secretaria de Estado de Educação, o Consulado Geral da França no Rio de Janeiro e a Académie de Créteil, em Paris, França, sendo o primeiro Colégio Público Bilíngue Português-Francês do Brasil.

Como base teórica, o presente trabalho discute os desafios de Educação Ambiental no ambiente escolar, no instante em que se insere no contexto político pedagógico da escola. A incumbência de avaliar a inclusão da Educação Ambiental como práxis pedagógica se faz necessária ao presumir que ela é base conceitual para o desenvolvimento de novos instrumentos de EA, como no caso das Trilhas Interpretativas

O processo metodológico da pesquisa foi construído de acordo com as propostas pedagógicas da escola e com os objetivos de pesquisa das instituições envolvidas. Através de metodologia participativa, os alunos foram acompanhados e avaliados, através de palestra, oficinas, saídas de campo e questionários. Como resultado da observação dessas atividades, uma trilha interpretativa foi elaborada. Almeja-se que os próprios alunos desenvolvam diferentes trilhas interpretativas, divididas por grupos temáticos: fauna, flora, aspectos geográficos e aspectos sociais.

O trabalho, ao todo, busca analisar os efeitos da ferramenta $\mathrm{TI}$ como promotora da Educação Ambiental, discutindo e avaliando, de maneira comparativa e complementar, as trilhas desenvolvidas nos dois momentos da pesquisa. Ao final, será produzido um protocolo de elaboração de trilhas interpretativas, a fim de consolidá-las como prática pedagógica viável de ser executada por professores e educadores. Dessa forma, espera-se promover a ferramenta interpretativa como instrumento de interação da sociedade com diversos contextos que envolvem uma área natural protegida, avaliando seu potencial em proporcionar conhecimento crítico, transformação social e apoio na gestão das unidades de conservação, obedecendo aos preceitos que uma área protegida estabelece.

\section{Referencial Teórico}

\section{A Educação Ambiental e suas vertentes}

Loureiro (2007), ao delimitar o conceito de Educação Ambiental, aponta a necessidade desta práxis pedagógica "vincular os processos ecológicos aos sociais na leitura de mundo, na forma de intervir na realidade e de existir na natureza" (LOUREIRO, 2007, p. 66). O campo social está tão inserido nas questões ambientais que na Estratégia Nacional para comunicação e Educação Ambiental, em seu documento preliminar de 2009 (MMA), as Unidades de Conservação são apontadas como cenários sociais, pois segundo o documento: 
Políticas e projetos de comunicação e Educação Ambiental devem buscar uma compreensão das UCs que ultrapassem sua concepção como espaços de preservação de ecossistemas e de seus recursos naturais, mas considerá-las como espaços de relações socioambientais historicamente configurados e dinamicamente movidos pelas tensões e conflitos sociais, integrando-a ao desenvolvimento regional, fortalecendo as interações sociais e a participação cidadã de todos os segmentos envolvidos (MMA, 2009, p.09).

Sorrentino (1997), ao observar a grande riqueza de diversidade de ações educacionais voltadas à questão ecológica/ambiental, ampliadas pela inclusão de mais atores proponentes de iniciativas na área, como órgãos públicos, municipais, estaduais, federais e internacionais, apontou a existência de quatro grandes correntes educacionais: a "conservacionista", a "educação ao ar livre", a "gestão ambiental" e a "economia ecológica". Vale ressaltar que os aspectos relacionados à corrente de "educação ao ar livre" incluíam os grupos de "caminhadas ecológicas", "trilhas de interpretação da natureza", "turismo ecológico".

A síntese dessas vertentes é defendida por Layrargues e Lima (2011), ao apontarem a tendência socioambiental dos educadores a partir dos anos 1990. Os autores reduzem, a partir da função social, as visões educacionais em duas orientações fundamentais: a EA convencional, associada a interesses conservadores da sociedade, e EA crítica, associada à transformação social, fundamentalmente. De fato, a Educação Ambiental conservadora era a corrente de pensamento mais amplamente utilizada na época, uma vez que a prática educativa era apoiada no objetivo de despertar uma nova sensibilidade humana para com a natureza, difundindo a lógica do "conhecer para amar, amar para preservar", orientada pela conscientização "ecológica" e tendo por base a ciência ecológica.

Há, portanto, diferenças centrais nesses objetivos. A EA Convencional ou Conservacionista visa à mudança ambiental, que deverá ocorrer por meio do apelo à moral e mudança de comportamentos individuais, como relatam Layrargues e Lima (2011). Os autores afirmam que esta tendência é histórica, forte e bem consolidada, mas não tende a ser hegemônica no campo, na primeira década do século XXI. Loureiro (2007) alerta que a EA Conservacionista, ao "biologizar" os processos sociais,

[...] reduz tudo a uma visão funcionalista de sociedade, estabelecendo analogias generalizantes entre sistemas complexos e autorregulados distintos e ignorando a função social da atividade educativa, numa sociedade economicamente desigual e repleta de preconceitos culturais (LOUREIRO, 2007, p. 67).

Já a abordagem da EA Crítica se orienta para a mudança social e ambiental, atuando na esfera política e ressaltando a leitura crítica da realidade (LAYRARGUES; LIMA 2011). Em relação a EA Crítica, a preocupação central da sua abordagem procura percorrer todos os campos da ciência, buscando identificar os diversos sujeitos envolvidos nos impactos ao meio ambiente e demonstrar que a vulnerabilidade de alguns grupos sociais frente a outros. Portanto, podemos afirmar que: 
"[...]a Educação Ambiental crítica é bastante complexa em seu entendimento de natureza, sociedade, ser humano e educação, exigindo amplo trânsito entre ciências (sociais ou naturais) e filosofia, dialogando e construindo pontes e saberes transdisciplinares (LOUREIRO, 2007, p.68).

A EA Crítica se funde a prática pedagógica ao problematizar, segundo o autor, as novas relações sociais na natureza em várias dimensões (cultural, econômica, política, legal, histórica, geográfica, estética etc.). Pode-se considerar, portanto, que a EA crítica rompe com a tendência da EA convencional.

Lima (2011) relata que a EA Conservacionista se desenvolveu como prática pedagógica centrada no ensino de ecologia, enquanto a EA Crítica procurar refletir sobre os sistemas sociais e a relação deles com os sistemas naturais. Atualmente a prática pedagógica se aproxima do ensino convencional, visto que concepção conservadora da EA, segundo Lima (2011) tem como uma de suas características a "concepção reducionista e fragmentada da questão ambiental" e "uma baixa incorporação de princípios e práticas interdisciplinares" (LIMA, 2011, p. 170-171). Loureiro (2007, p. 69) afirma que:

[...] é preciso dialogar com o mundo da educação e intervir nas políticas públicas para que práticas viáveis sejam democratizadas. $\mathrm{E}$ o principal: a perspectiva ambiental passa a fazer parte ativa dos projetos políticos-pedagógicos (PPP) permeando a instituição escola em seu pulsar.

Nesse sentido, o presente trabalho busca a interlocução entre os objetivos da EA, e os objetivos pedagógicos da escola, a fim de gerar uma relação mutuamente benéfica para as instituições envolvidas. $O$ trabalho obedece à proposta pedagógica da escola, buscando inovação e diálogo ao propor a construção de trilhas interpretativas aos moldes da EA Crítica, interdisciplinar. A pesquisa, tendo como viés central as trilhas interpretativas e sua construção, busca avaliar o potencial difusor da EA nas práticas escolares.

\section{Uso Público e as trilhas em Parques}

A criação de áreas protegidas, a partir da implementação dos parques nacionais, ainda no século XIX, se consolidou como uma das principais formas de intervenção governamental na gestão do meio ambiente. No Brasil, a promulgação do Sistema Nacional de Unidades de Conservação (Lei 9.985/2000) prevê a preservação ambiental aliada a diferentes formas de uso público.

Nesse sentido, entende-se o Uso Público como um processo de visitação das áreas protegidas, podendo se manifestar como atividades educativas, de lazer, esportivas, recreativas, científicas e de interpretação ambiental, que proporcionam ao visitante a oportunidade de conhecer, entender e valorizar os recursos naturais e culturais existentes (VALLEJO, 2013; MINISTÉRIO DO MEIO AMBIENTE, 2006).

O Parque é a categoria mais antiga das Unidades de Conservação, Segundo Rugine e Pires (2018): 
O primeiro Parque Estadual surgiu no Brasil em 1896, em São Paulo, criado pelo naturalista e botânico sueco Alberto Löfgren. O Parque Alberto Löfgren, ou Horto Florestal, ocupa o primeiro lugar do ranking de Parques Estaduais mais visitados, recebendo em média 720.000 visitas por ano. Sucedendo-o, encontram-se o Parque Estadual Mãe Bonifácia (MT) e o Parque Estadual Dunas de Natal (RN), que atendem 240.000 e 107.644 visitantes/ano, respectivamente" (RUGINE; PIRES, 2018, p. 64 apud RODRIGUES, 2005, p. 28).

Vallejo (2013, p.16) destaca que "de todas as UC do sistema nacional, os parques públicos são os mais populares e sobre eles recaem as maiores atenções em relação ao uso recreativo e turístico". Logo, há necessidade de estabelecer mecanismos de controle de impactos resultantes do Uso Público em Parques.

Em relação as trilhas em territórios protegidos, Andrade e Rocha (2008) também consideram a categoria Parque seu exemplo mais sagrado de implementação e planejamento. Ao tratar do planejamento das trilhas, Andrade (2008) as considera como instrumentos de manejo nas áreas do Parque, pois se por um lado representam uma interferência do homem na natureza, por outro restringem esta interferência a um único e delimitado itinerário, preservando a área adjacente (ANDRADE, 2008, p. 4).

Em uma abordagem mais geral, o conceito de trilha, segundo Vasconcellos (2006) é explicado como um caminho através de um espaço geográfico, histórico ou cultural. Eisenlohr et al. (2013) também evidenciam o elemento cultura na trilha, servindo como via de comunicação entre os diversos lugares habitados pelo homem e suprindo a necessidade de deslocamento, reconhecimento de novos territórios e busca por alimento e água.

$\mathrm{Na}$ lógica do manejo, Eisenlohr et al. (2013) analisam as trilhas como lócus para ações de Educação Ambiental, tanto para o ensino formal quanto para o não formal. Os autores citam que a Educação Ambiental em trilhas:

[...] deve ir além de simplesmente ensinar o que os visitantes devem fazer nos ambientes visitados, mas também propor mudanças no modo como as pessoas pensam e avaliam a sua relação com o ambiente (EISENLOHR et al., 2013, p apud CAMPOS; FILLETO 2011, p.409).

Nesse sentido, a atividade de trilhas interpretativas prevista nesta pesquisa, visa corroborar com a gestão da uc ao incentivar o aumento de práticas de uso público coerentes com o previsto no plano de manejo do Parque.

\section{Interpretação Ambiental}

No ambiente da EA, existem diversas ferramentas que podem e devem ser utilizadas para atingirem os objetivos previstos, visto que apenas trabalhos teóricos em muitos casos distanciam a sociedade do ambiente. Uma das formas de se trabalhar as questões ambientais de maneira prática e ativa, em campo, é utilizando a ferramenta Interpretação Ambiental (IA), caracterizada como um meio efetivo para se promover a interação entre os diferentes grupos e suas relações com o meio ambiente (BRASIL, 2005). 
Em 1957 foi proposta uma definição formal para interpretação por Freedman Tilden, que visualizou a interpretação ambiental como:

uma atividade educativa que aspira revelar os significados e as relações existentes no ambiente, por meio de objetos originais, através de experimentos de primeira mão e meios ilustrativos, em vez de comunicar informação literal (TILDEN, 1977).

Vasconcellos (2006) aponta que a interpretação ambiental traduz a linguagem da natureza para a linguagem comum das pessoas, revelando um mundo antes despercebido. A abordagem interpretativa, ou seja, "a linguagem ou forma própria com que a interpretação aborda os fatos, cativa, provoca e estimula a reflexão" (VASCONCELLOS, 1998, p. 24), precisa apresentar algumas características próprias. Ham (1992 apud VASCONCELLOS 1998, p.24) estabelece 4 características básicas para a abordagem interpretativa:

Ser amena (mantendo a atenção da audiência através da informalidade, do tom de voz amistoso, do movimento, cores vivas, humor, música, interação). Ser pertinente (sendo significativa e pessoal), organizada (utilizando categorias lógicas, como títulos e subtítulos, início, meio e fim) e ser temática (tendo uma mensagem a ser comunicada) (HAM, 1992 apud VASCONCELLOS, 1998, p. 24).

A Interpretação Ambiental também está prevista como objetivo da Política Nacional do Turismo (PNT), estabelecida pela Lei no 11.771, de 2008. Como previsto, a PNT deve:

[...] propiciar a prática de turismo sustentável nas áreas naturais, promovendo a atividade como veículo de educação e interpretação ambiental e incentivando a adoção de condutas e práticas de mínimo impacto compatíveis com a conservação do meio ambiente natural (MINISTÉRIO DO TURISMO, 2010, p.41).

Pedrini (2007), em seu estudo sobre a elaboração de guia didático para Interpretação Ambiental em trilhas, concluiu que a prática da IA pode ser realizada ao longo de uma trilha, enquanto a Educação Ambiental, como processo, deve ser realizada permanentemente na vida dos visitantes, até pelo fato da EA ter um caráter multidimensional. $\mathrm{O}$ autor aponta para a necessidade, portanto, das ações de IA estarem alinhadas as práticas de ecoturismo no cenário brasileiro.

\section{Programas de Interpretação Ambiental}

Como Vasconcellos (2006) aponta, "os programas de Educação/Interpretação Ambiental devem ser elos entre a área protegida e a população, conciliando a demanda e a satisfação do usuário com a conservação da área" (VASCONCELLOS, 2006, p. 16), variando de acordo com a categoria de manejo e objetivos específicos de cada área protegida. Estes Programas, segundo Vasconcellos (2006), podem otimizar a distribuição dos visitantes e das ações dos órgãos gestores, propiciando a 
redução dos impactos negativos nos recursos naturais, auxiliando na conservação da área protegida.

Os Programas Interpretativos nas UC deverão funcionar, segundo Vasconcellos (2006), como instrumentos educativos para os diversos públicos visitantes, sendo constituído por um conjunto de estratégias planejadas e desenvolvidas para atingir o objetivo maior. A autora cita vários trabalhos que recomendam os passos básicos para o planejamento de um Programa Interpretativo (Tabela 1).

Tabela 1: Passos para o planejamento do Programa de Interpretação Ambiental. Table 1: Steps for planning the Environmental Interpretation Program.

\begin{tabular}{|c|c|}
\hline $\begin{array}{c}\text { Perguntas para Elaboração do } \\
\text { Programa de Interpretação }\end{array}$ & Resultado \\
\hline $\begin{array}{l}\text { O quê? } \\
\text { Para quem? }\end{array}$ & $\begin{array}{l}\text { Identificação das oportunidades e problemas } \\
\text { Identificação do público }\end{array}$ \\
\hline Para quê? & $\begin{array}{l}\text { Identificação dos objetivos ou resultados } \\
\text { esperados para cada público }\end{array}$ \\
\hline $\begin{array}{l}\text { Como? } \\
\text { De que forma?Quem?Quando?Onde? }\end{array}$ & $\begin{array}{l}\text { Escolha do tema ou mensagem } \\
\text { Seleção das atividades, meios, técnicas a } \\
\text { serem utilizados na transmissão das } \\
\text { mensagens. }\end{array}$ \\
\hline E depois? & $\begin{array}{l}\text { Avaliação dos resultados e reformulação do } \\
\text { Programa, caso necessário. }\end{array}$ \\
\hline
\end{tabular}

Fonte: Adaptado de Vasconcellos, 2006.

Source: Adapted from Vasconcellos, 2006

Como apresentado na tabela acima, o Programa de Interpretação Ambiental inicia-se com o diagnóstico do local em que se está planejando, de acordo com os aspectos tangíveis (recursos naturais e culturais) e intangíveis (inter-relações, processos, história) da área e seu entorno. O conhecimento sobre as características do público, a seguir, é fundamental para a pertinência do Programa. É importante caracterizar o público segundo a idade, nível cultural, procedência, tempo disponível e interesses, por exemplo. Os objetivos esperados no final do programa também precisam ser estabelecidos, descrevendo quais mudanças de comportamentos ou situação o programa pretende alcançar. A escolha do tema de IA é o ponto básico do Programa, pois são através das mensagens transmitidas que os resultados esperados serão alcançados. Para tal, a escolha das estratégias para 0 desenvolvimento eficaz do tema selecionado se faze indispensável. Vasconcellos (2006, apud HAM,1992; BECK; CABLE,1998; SALGADO, 2000; DIETZ; TAMAIO, 2000) aponta que o meios interpretativos podem ser classificados em personalizados e não personalizados (Tabela 2). Por último, a avaliação dos resultados, como processo contínuo, permite a reflexão e ajustamento do Programa, adequando-o com os objetivos propostos. 
Tabela 2: Metodologias de Interpretação.

Table 2: Interpretation Methodologies.

\begin{tabular}{|c|c|c|c|}
\hline Meios de Interpretação Personalizados & $\begin{array}{l}\text { Meios } \quad \text { de } \\
\text { Personalizados }\end{array}$ & Interpretação & Não \\
\hline Presença de educador-intérprete & $\begin{array}{l}\text { Apenas materiais } \\
\text { Interpretacão }\end{array}$ & e equipamentos & para \\
\hline Trilhas Guiadas & Trilhas Autoguiadas & & \\
\hline Palestras & Exposições & & \\
\hline Teatro & Painéis & & \\
\hline Oficinas & Cartazes & & \\
\hline Representações & Publicações interativas & & \\
\hline
\end{tabular}

Fonte: Adaptado de Vasconcellos, 2006.

Source: Adapted from Vasconcellos, 2006.

As Trilhas Interpretativas, portanto, estão relacionadas ao instrumento de Interpretação Ambiental. Como ferramenta de Educação Ambiental, deve ser desenvolvida por diferentes metodologias em um processo contínuo de construção e avaliação. As Trilhas Interpretativas surgem com uma das formas de aplicação dos conceitos de Interpretação Ambiental e podem se configurar como metodologia de Interpretação Ambiental mais utilizada e difundida nas ações de Uso Público nacionais, apesar de ser muitas vezes confundida com simples atividades de condução por trilhas nos ambientes naturais protegidos.

\section{As Trilhas Interpretativas}

No que se refere às ações de Interpretação Ambiental alinhadas aos processos de Educação Ambiental dentro de Unidades de Conservação, pode-se citar a ferramenta das Trilhas Interpretativas (TI). Elas são definidas como atividades de interpretação ambiental que proporcionam o contato direto entre os indivíduos e o ambiente natural, através da construção de conhecimentos, da sensibilização, da reflexão crítica e da noção de pertencimento. Ikemoto et al. (2009) afirma que as trilhas interpretativas são caracterizadas por serem temáticas e organizadas, e acima de tudo, por buscar associar o conteúdo com a experiência e vivência do visitante, promover o questionamento e a reflexão através de recursos didáticos diversos, diferenciar e adequar as abordagens em função das características dos observadores e trabalhar os temas de forma inter-relacionada, utilizando a trilha como principal instrumento de sensibilização.

As trilhas podem ser subclassificadas quanto aos recursos de interpretação ambiental de duas maneiras: guiadas ou autoguiadas. As trilhas guiadas são realizadas com acompanhamento de um guia/condutor, tecnicamente capacitado para estabelecer um bom canal de comunicação entre o ambiente e o visitante, oferecendo segurança a todos na caminhada (ANDRADE; ROCHA, 2008, p. 6). As trilhas autoguiadas permitem o contato do visitante e o meio ambiente sem a presença de um guia. Recursos visuais, gráficos e outros orientam a caminhada, com informações de direção, distância, elementos a serem destacados e os temas desenvolvidos (op. citado, 2008, p. 6). Nesse sentido, Vasconcellos (2006) também estabelece alguns métodos de trilhas interpretativas, caracterizadas como: guiadas, autoguiadas, autoguiadas com placas/painéis interpretativos e autoguiadas com folhetos interpretativos, como apresentado anteriormente. Vasconcellos (2006) divide as trilhas interpretativas ainda de acordo com a metodologia de aplicação (Tabela 3). 
Tabela 3: Metodologias de aplicação nas Trilhas Interpretativas.

Table 3: Application Methodologies in the Interpretive Trails.

\begin{tabular}{ll}
\hline Trilhas autogiadas & $\begin{array}{l}\text { Trilhas com pontos de parada marcados, } \\
\text { onde o visitante, auxiliado por placas, painéis } \\
\text { ou folhetos, explora o percurso sem guia; }\end{array}$ \\
\hline $\begin{array}{l}\text { Trilhas autoguiadas com } \\
\text { placas/painéis interativos }\end{array}$ & $\begin{array}{l}\text { Tema desenvolvido por mensagens gravadas em } \\
\text { placas ou painéis colocados em pontos }\end{array}$ \\
$\begin{array}{l}\text { Trilhas autoguiadas com } \\
\text { folhetos interpretativos }\end{array}$ & $\begin{array}{l}\text { Tema é desenvolvido em um folheto explicativo, } \\
\text { contendo referência aos pontos de parada. Os } \\
\text { folhetos podem conter mensagens mais } \\
\text { detalhadas do que as placas, sendo possível que } \\
\text { temas diferentes possam ser desenvolvidos nos } \\
\text { mesmos pontos de parada. }\end{array}$ \\
\hline
\end{tabular}

Fonte: Adaptado de Vasconcellos, 2006.

Source: Adapted from Vasconcellos, 2006.

As Trilhas Interpretativas, portanto, estão relacionadas ao instrumento de Interpretação Ambiental. Como ferramenta de Educação Ambiental, devem ser desenvolvidas por diferentes metodologias, em um processo contínuo de construção e avaliação. Nessa lógica, elas surgem com uma das formas de aplicação dos conceitos de Interpretação Ambiental e podem se configurar como metodologia de Interpretação Ambiental mais utilizada e difundida nas ações de Uso Público nacionais, apesar de ser muitas vezes confundida com simples atividades de condução por trilhas nos ambientes naturais protegidos.

\section{Metodologia}

\section{Área de estudo}

O Parque Estadual da Serra da Tiririca (PESET) é uma unidade de conservação de proteção integral, estabelecida pela Lei ํo 1.901, de 29 de novembro de 1991. A criação da UC teve por finalidade "proteger a flora, a fauna e as belezas cênicas nele existentes, bem como contribuir para a amenização climática, a recarga natural do lençol freático e a redução da erosão na região onde está inserido" (INEA, 2015). Segundo o Instituto Estadual do Ambiente, órgão responsável pela gestão das unidades de conservação Estaduais do Rio de Janeiro, - PESET contém resquícios de Mata Atlântica, inúmeras espécies endêmicas, costões rochosos, restingas, o que o torna um patrimônio natural brasileiro e uma área de crescente interesse para a pesquisa científica, ecoturismo, recreação e Educação Ambiental (INEA, 2015).

No PESET foram elencadas 12 áreas de visitação, totalizando 331,71 ha, o que corresponde a aproximadamente $9,5 \%$ da área total do parque. A área do Costão de Itacoatiara encontra-se na zona de conservação da UC com maior visitação do Parque, com 98,8 ha. 


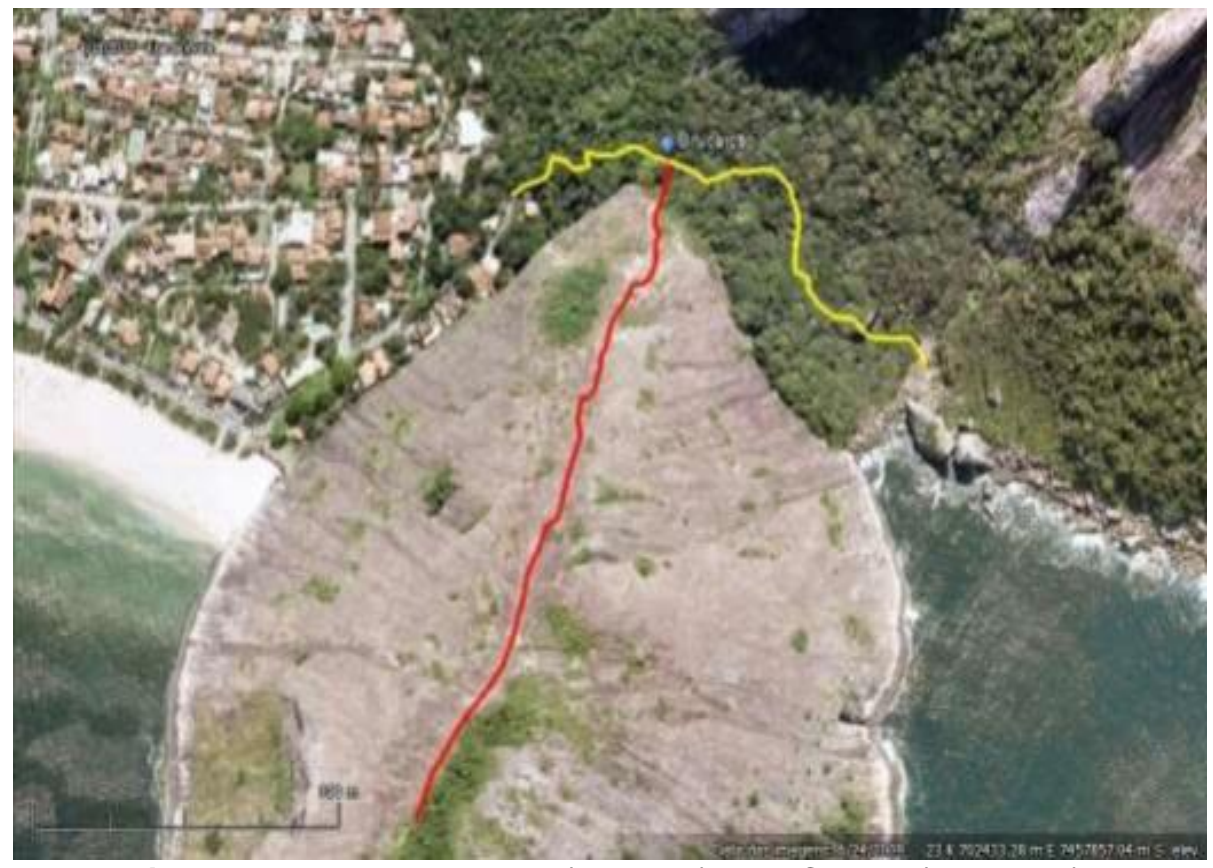

Figura 1: Trilha do Bananal (amarelo) e do Costão (vermelho).

Figure 1: Bananal (yellow) and Costão (red) trail.

Fonte: Cova e Pimentel, 2013.

Source: Cova e Pimentel, 2013.

A trilha do Costão de Itacoatiara, onde as trilhas interpretativas estão sendo elaboradas, é também conhecida como Morro do Tucum. A trilha está localizada entre a Pedra do Elefante e a Praia de Itacoatiara, uma das praias mais frequentadas de Niterói. O nome do bairro onde está o Costão, Itacoatiara, que também denomina a praia, é de origem tupi, e significa pedra lavrada, escrita, pintada ou debuxada. Deve-se provavelmente aos riscos em sua superfície, desenhados pela natureza durante milhares ou milhões de anos.

Essas encostas são muito procuradas, principalmente nos finais de semana, tanto pelos caminhantes que sobem a crista inclinada, quanto pelos escaladores que desafiam as faces de granito mais verticais, todos querendo chegar ao alto para apreciar a vista e o famoso pôr do sol. Todo o percurso da trilha do Costão apresenta 811 metros e seu cume está a 217 m de altitude (INEA, 2015).

Na trilha do Costão, no bairro de Itacoatiara, o Plano de Manejo do PESET estabelece que a área tem:

[...] grande beleza cênica, inclusive pela cobertura vegetal que mescla floresta ombrófila e vegetação rupícola. Tem grande afluxo de visitantes (o maior do parque atualmente) e ao mesmo tempo constitui uma das áreas de maior importância para preservação da UC, especialmente pelos quesitos de fragilidade da fauna e flora. A área contém as principais trilhas de acesso e vias de escalada do PESET, incluindo o "campo-escola" do Bananal, o Costão de Itacoatiara e o acesso pela face sul do Alto Mourão (INEA, 2015, P. 349).

Por esses motivos, e por ainda não possuir nenhuma trilha interpretativa elaborada, o trabalho, por escolha conjunta entre pesquisadores, alunos e colégio, 
será realizado nesta trilha do parque, procurando associar a trilha, tida como verdadeiramente turística, a uma visão pedagógica e socioambiental, com base nas trilhas interpretativas apresentadas por Pimentel et. al (2017).

\section{Fases da Pesquisa}

A metodologia participativa do trabalho é baseada no modelo de pesquisa de Boterf (1987) constituído por quatro fases: (1) montagem institucional e metodológica; (2) estudo preliminar e provisório da região e populações envolvidas; (3) análise crítica dos problemas que a população considera prioritário e que desejam estudar e desenvolver e (4) aplicação de um plano de ação.

$\mathrm{Na}$ montagem institucional e metodológica (Fase 1), foram realizadas pesquisas bibliográficas sobre os temas pertinentes da pesquisa, como as Unidades de Conservação de Proteção Integral, o Parque Estadual da Serra da Tiririca e as questões que envolvem o Uso Público, como Educação Ambiental e a Interpretação Ambiental. Para traçar os objetivos da pesquisa, um cronograma de atividades foi instituído junto ao CIEP. Vale ressaltar que este trabalho é fruto de um projeto firmado entre o CIEP-449 Governador Leonel de Moura Brizola Brasil-França e o Grupo de Estudos Interdisciplinares do Ambiente (GEIA), localizado na Faculdade de Formação de Professores (FFP) da Universidade do Estado do Rio de Janeiro (UERJ).

Ainda de acordo com a Fase 1 da pesquisa participativa, foi definida a metodologia para implementação das trilhas interpretativas. Os pontos de interesse para elaboração das trilhas interpretativas foram levantados e avaliados com base no método de Indicadores de Atratividade de Pontos Interpretativos (IAPI) (MAGRO; FREIXÊDAS, 1998), considerando sua importância educacional, seus atrativos, beleza cênica, distância entre diferentes pontos e de modo em que o mesmo tópico não fosse abordado mais de uma vez. A adaptação da metodologia IAPI, descrita por Magro e Freixêdas (1998) teve a finalidade de otimizar a escolha dos pontos interpretativos. Como a característica do trabalho é dar independência aos alunos na elaboração das trilhas interpretativas, foi apresentado e utilizado o IAPI apenas como base metodológica, aberta a novas formas de aplicação. A metodologia se baseia em cinco etapas: Fase 1 - Levantamento dos pontos potenciais para a interpretação; Fase 2 - Levantamento e seleção de indicadores; Fase 3 - Elaboração da Ficha de Campo; Fase 4 - Uso da Ficha de Campo; Fase 5: Seleção Final.

Durante a etapa do estudo preliminar e provisório da região e populações envolvidas (Fase 2), foram realizadas diversas atividades com a turma, a fim de analisar o conhecimento prévio dos alunos e o interesse deles pelos temas abordados (Figura 2). Dentre as atividades, uma palestra foi ministrada para os alunos, apresentando-os aos conceitos levantados na pesquisa bibliográfica. Também nesta etapa, foi definida pelos alunos a trilha do Costão de Itacoatiara para a implementação das trilhas interpretativas. Ao final do dia, foram feitas duas oficinas interativas com os alunos, uma sobre o Parque Estadual da Serra da Tiririca e outra abordando os biomas brasileiros. 


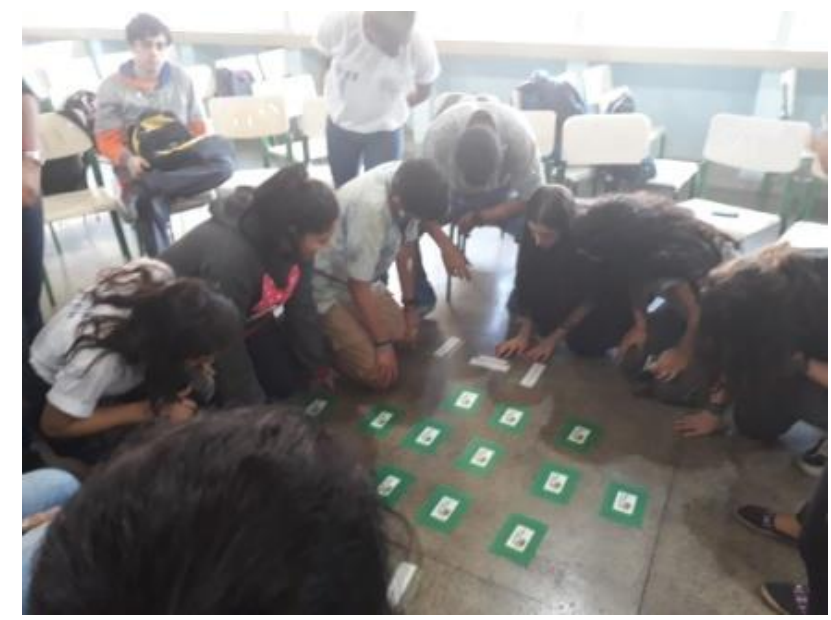

Figura 2: Oficinas durante as atividades na escola. As oficinas consistiram na abordagem sobre a biodiversidade do Parque Estadual da Serra da Tiririca e os conceitos de Bioma, diferenças e principais características.

Figure 2: Workshops during school activities. The workshops consisted of the Serra da Tiririca State Park biodiversity approach and the concepts of biome, differences and main characteristics.

Fonte: Arquivos do Geia, 2018.

Source: Geia Archives, 2018

Ainda caracterizando a Fase 2 da pesquisa participativa, foi realizada uma saída de campo preliminar a trilha do Costão de Itacoatiara (Figura 3). Esta atividade contou com a participação de membros da Gestão do Parque, pesquisadores da Universidade do Estado do Rio de Janeiro e o professor de biologia da escola. Foram observadas as características da trilha, os possíveis pontos interpretativos, e prováveis questões de interesse dos alunos.

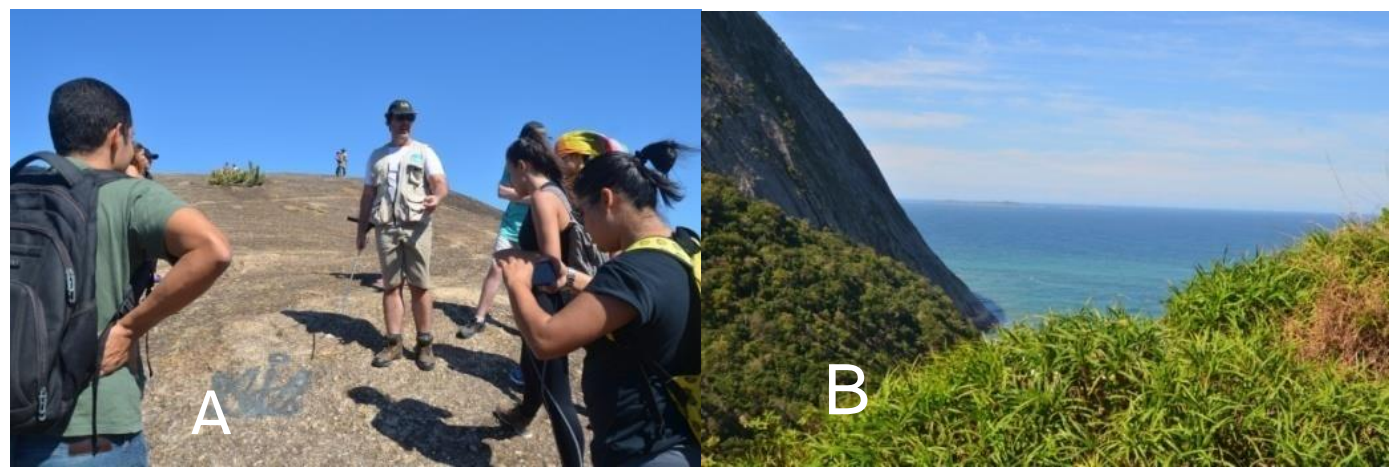

Figura 3: Primeira saída de campo. (A) Ponto de pichação na subida da trilha do Costão; (B) vista para Enseada e a vegetação rupícula, típica de afloramentos rochosos.

Figure 3: First Field Exit. (A) Graffiti point on the way up the Costão Trail; (B) View of Cove and the rupiculate vegetation, typical of rocky outcrops.

Fonte: Arquivos do Geia, 2018.

Source: Geia Archives, 2018

No que se refere a análise crítica dos problemas que a população considera prioritário e que desejam estudar e desenvolver (Fase 3), foi realizada uma nova saída de campo, agora com a presença da turma, favorecendo a observação na prática do conteúdo trabalhado com os alunos ao longo da pesquisa (Figura 4). Nesta etapa, os alunos puderam observar os mais diferentes aspectos da trilha 
escolhida. Além disso, através de observação direta dos alunos, foi possível constatar alguns pontos principais de interesse da turma durante toda a atividade, como as pichações das pedras, a vegetação fragmentada (ilhas de vegetação), a diferença entre a vegetação do início da trilha do bananal com a vegetação típica do Costão, a lagoa de Itaipu e seu entorno, e o cume do costão, contemplando a paisagem e a praia de Itacoatiara. A observação direta dos alunos se faz necessária para contextualizá-los na pesquisa e, assim, conseguir elaborar uma trilha interpretativa que atenda aos interesses da turma.

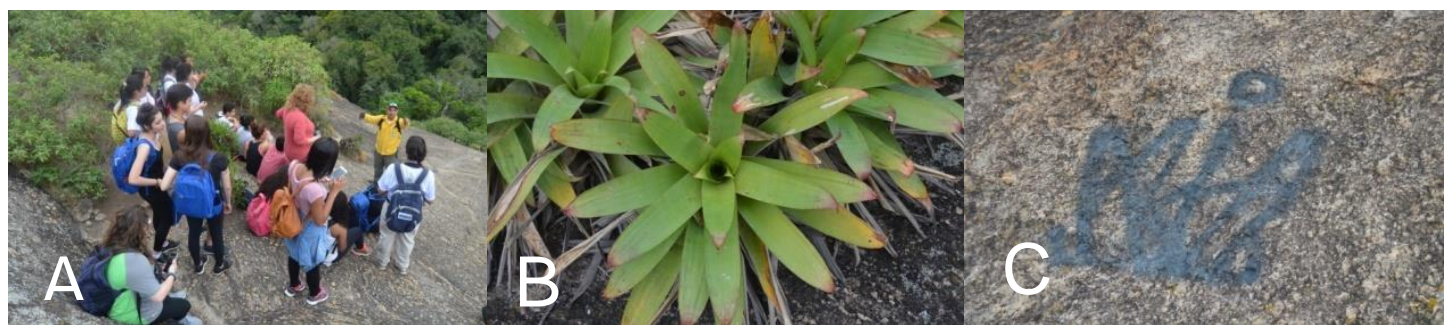

Figura 4: Saída de campo com os alunos. (A) A atividade foi acompanhada por um guarda-parque do PESET; (B) Predominância de bromélias também foi apontada pelos alunos; (C) Exemplo de impactos na trilha. A pichação chamou atenção dos alunos durante o campo.

Figure 4: Field trip with students. (A) The activity was accompanied by a PESET ranger; (B)

Predominance of bromeliads was also pointed out by the students; (C) Example of impacts on the trail. The graffiti caught the attention of the students during the field.

Fonte: Arquivos do Geia, 2018.

Source: Geia Archives, 2018.

Ainda a fim de analisar o contexto social da turma e seus interesses (Fase 3), foram aplicados questionários em cada momento da pesquisa. $O$ primeiro questionário foi respondido no dia da palestra e objetivou o conhecimento prévio dos alunos sobre temas como trilhas interpretativas, Unidades de Conservação e conceitos de bioma, principalmente. Um segundo questionário foi distribuído, antes da saída dos alunos a campo, voltado para os conhecimentos acerca da região do Parque e expectativas sobre a atividade.

$\mathrm{Na}$ Fase 4, como plano de ação, foi elaborado uma trilha interpretativa na trilha do Costão de Itacoatiara, baseada nas observações diretas, questionários e atividades práticas realizadas nas etapas anteriores. Os alunos, públicos alvo desta fase, poderão observar, na prática, a aplicação de uma trilha interpretativa, servindo de base para as trilhas interpretativas que desenvolverão após esta etapa.

\section{Resultados e discussão}

A partir de um diagnóstico resultante das diversas etapas já realizadas da pesquisa, foi possível traçar o histórico social da turma e os objetivos pedagógicos da escola, a fim de subsidiar uma discussão acerca da possibilidade de inclusão da ferramenta trilhas interpretativas como prática didática. Assim, uma proposta de Trilha Interpretativa no Costão de Itacoatiara foi definida e será implementada com a turma de Ensino Médio do CIEP Brasil-França. Os seis pontos de interpretação foram determinados a partir da coleta de dados em campo com o diagnóstico relacionado aos objetivos pedagógicos da escola e ao conhecimento prévio dos alunos. 


\section{Considerações para a interpretação ambiental nas trilhas}

Nesta etapa, foram aplicados questionários com a turma a fim de analisar o conhecimento prévio dos alunos aos temas relacionados e propor reflexões para a implantação das trilhas interpretativas. Quando perguntados sobre ter conhecimento da existência de Unidades de Conservação no Brasil, metade da turma presente respondeu afirmativamente $(50 \%, \mathrm{~N}=6)$, porém desconheciam o Parque Estadual da Serra da Tiririca, $69 \%(\mathrm{~N}=9)$. Com relação à pergunta que associava seus conhecimentos ao bioma Mata Atlântica, 54\% disse desconhecer esse bioma, característico do Estado do Rio de Janeiro, fundamentando a importância da oficina aplicada. Sobre as Trilhas Interpretativas, muitos consideravam as Tls como "uma forma de conhecer a fundo os locais visitados". Ao serem indagados sobre as expectativas em fazer a trilha interpretativa, os aspectos da fauna e flora estiveram presentes em todas as respostas e, em alguns casos, os alunos esperavam conhecer as "curiosidades e características da área" e "a formação da área e como é feita sua preservação". Esse fato pode ser explicado pela forma em que são abordadas as disciplinas em sala de aula e pelo fato de as Unidades de Conservação ainda serem vistas e tratadas como ambientes naturais fora do contexto social, histórico e cultural.

No segundo questionário, constatou-se que muitos já estiveram no bairro de Itacoatiara pelo menos uma vez $(62 \%, \mathrm{~N}=15)$, principalmente para ir à praia $(93 \%$, $\mathrm{N}=14$ ), porém poucos já haviam ido a trilha do Costão. Ou seja, a atividade de trilha interpretativa foi responsável por levar a maioria dos alunos pela primeira vez ao costão de Itacoatiara $(75 \%, \mathrm{~N}=18)$. Ao priorizarem suas expectativas com a região do Costão de Itacoatiara, os aspectos biológicos mais uma vez prevaleceram, com $50 \%(\mathrm{~N}=12)$ de respostas, seguido pelo interesse em apreciar a natureza, com $29 \%$ $(\mathrm{N}=7)$, onde apenas $4 \%(\mathrm{~N}=1)$ apontaram a prática de diversos conhecimentos (biológicos, geográficos e históricos) como motivo principal em suas expectativas. A divisão da $\mathrm{TI}$ por temas também pode ter favorecido o grande foco biológico da pesquisa, além do enraizado ponto de vista da UC como espaço verde preservado, e não um território com múltiplas relações.

\section{A Trilha Interpretativa}

A trilha interpretativa foi elaborada com base nos pontos de atratividade para futuras visitações escolares com foco em EA. Os pontos podem ser explorados didaticamente, em especial, no ensino formal, com a presença de um professor ou um educador.

Como resultado da pesquisa, também será trabalhado um protocolo para elaboração de Trilhas Interpretativas. Espera-se que o material didático sirva de base para novas iniciativas de implementação das trilhas interpretativas, nas mais diversas Unidades de Conservação. Além disso, o protocolo incentivará o uso da trilha do Costão de Itacoatiara, no PESET, por escolas e instituições de ensino que busquem, principalmente, uma atividade didática, pedagógica e interdisciplinar. Sua aplicação se propõe, portanto, a discutir as práticas pedagógicas atuais, associandoas aos contextos sociais e questões ambientais relevantes, em consonância às premissas de uso público estabelecidas nas unidades de conservação. 


\section{Pontos de interpretação}

A seguir se apresenta a descrição dos pontos interpretativos elaborados a partir da pesquisa participativa. Os pontos definidos foram: Ponto de partida Entrada da subsede do Parque; (1) Entre o Bananal e o Costão; (2) Corrimão "Rapel fixo" do Costão; (3) Ilhas de vegetação; (4) O entorno da Tiririca; (5) No cume do Costão. Ao todo, a atividade deverá durar $1 \mathrm{~h} 30$, com pausa ao final para um piquenique no alto do Costão.

\section{Ponto de partida: Entrada da Subsede do Parque}

O ponto inicial se dá logo na entrada para o Parque Estadual da Serra da Tiririca, no posto avançado de Itacoatiara. Neste ponto os alunos são informados sobre a atividade (duração, dificuldade) e orientados quanto a conduta correta que devem manter na trilha. Nesta etapa, será utilizado um mapa do Parque, localizado na entrada, para explicar a trilha que irá ser percorrida.

Como na mesma entrada é possível a realização de duas trilhas distintas ( a do Costão e a trilha do Bananal), é recomendado que no primeiro momento, os alunos observem as principais características que a trilha do bananal, obrigatória para chegar ao Costão.

Antes de começar a atividade, os intérpretes sugerem uma dinâmica denominada "anjo": há um sorteio fechado, estilo "amigo oculto"; cada aluno pegará um papel com o nome de um colega da turma; o aluno deverá ser o "anjo" do colega sorteado, sendo responsável por seu bem-estar durante todo o percurso. Ao final da atividade, todos devem tentar adivinhar quem era seu anjo. Esta é uma maneira dinâmica e fácil de manter o grupo unido.

\section{Ponto 1: Entre o Bananal e o Costão}

Após percorrer alguns metros na trilha do Bananal, encontra-se um platô de madeira, com pontos de repouso. Este é o marco de início da trilha do Costão. Neste ponto, são trabalhos temas relacionados aos impactos de visitação, utilizando como base a placa do início da trilha do Costão, com pichações e outras degradações. Também é debatido o tipo de vegetação observada até então no início da trilha, caracterizada como Floresta Ombrófila Densa, e suas principais características.

\section{Ponto 2: Corrimão "Rapel fixo" do Costão}

Ponto de interpretação na subida inicial da trilha do Costão. Esta parte conta com o auxílio recente de uma estrutura fixa, que delimita a passagem ao centro da trilha, evitando "trilhas sociais" laterais ao caminho, impactando a vegetação no entorno. Diniz (2016), em sua dissertação sobre o Diagnóstico de Visitação no Costão de Itacoatiara, cita que parte mais íngreme da subida do Costão, com $40^{\circ}$ de inclinação, é evitada pelos visitantes, que tendiam a percorrer a trilha no ponto de inclinação $30^{\circ}$, nas laterais. Tal fato, analisado pela autora, resultou em um aumento de $4 \mathrm{~m}^{2}$ de rocha exposta na subida do Costão, no período de sete meses de pesquisa, significando uma supressão da vegetação e substrato na borda da subida. Como medida emergencial da gestão do parque, a estrutura fixa delimita a área de pisoteio, possibilitando a recuperação na vegetação de borda. 


\section{Ponto 3: Ilhas de vegetação}

Ponto de destaque para o tipo de vegetação típica de afloramentos rochosos, destacando suas adaptações a solo raso e condições climáticas adversas, com pouca disponibilidade de água. Barros (2008) destaca que a floresta cria condições microclimáticas específicas protegendo a vegetação do afloramento rochoso. Ainda segundo a autora, a vegetação do PESET "formam ilhas entremeadas pela floresta, sendo ocupadas por comunidades de plantas rupícolas e saxícolas adaptadas às condições ambientais extremas" (BARROS, 2008, p. 142) Os aspectos adaptativos da vegetação presente em afloramentos rochosos também ganham destaque neste ponto. Barros (2008) aponta que a sobrevivência nesses ambientes implica numa série de adaptações que determinam à distribuição das plantas. O tipo de rocha, declividade, insolação e o grau de umidade são importantes na seleção das espécies.

Neste ponto, também são trabalhadas as questões de espécies endêmicas e espécies ameaçadas de extinção, exemplificada pela Vriesea costae, espécie vegetal símbolo do parque e endêmica dos afloramentos rochosos do entorno da Baía de Guanabara e que se encontra criticamente ameaçada. Nela, se encontra a perereca do litoral (Scinax littoreus), também considerada endêmica e que está representada como símbolo do Parque.

A predominância das bromélias foi uma característica bem marcante durante todo o campo. Barros (2003) destaca que a Bromeliaceae é um grupo em evidência no contexto da conservação, sendo considerado um importante indicador de diversidade. Em sua tese, em 2003, a autora concluiu que as Bromeliaceae dos afloramentos rochosos da Serra da Tiririca representam $61 \%$ do total de espécies levantadas dessa família no PESET e as Orchidaceae.

\section{Ponto 4: O Entorno da Tiririca}

Ponto de interpretação em que são abordados os aspectos sociais do Parque e histórico de criação, tendo como base a planta Cyperaceae, popularmente chamada de tiririca e que originou o nome da UC. No passado, a travessia da região de Niterói para Maricá era feita por caminhos de tropeiros que passavam pela Serra da Tiririca onde se observava uma grande quantidade dessa planta (BARROS; SEOANNE, 1999).

Além disso, com auxílio de um mapa da região, são trabalhados processo de urbanização da área, especulação imobiliária e a criação do PESET por manifestação popular, além da abertura da Lagoa de Itaipu e Piratininga e os conflitos sociais envolvendo os limites do parque e o território.

\section{Ponto 5: No cume do Costão}

Etapa final da atividade. Os conceitos de paisagem são centrais nesta etapa. Os alunos são orientados a observar a fauna no topo da trilha, considerando que dentro dos limites do parque são encontrados $22 \%$ da avifauna do Estado, abrigando 199 espécies (INEA, 2015). Além disso, aspectos de ecossistemas costeiros e marinhos, bem como características destes ecossistemas, são fundamentais para contextualizar a importância do PESET quanto a sua biodiversidade. Ao final, a dinâmica de identificação dos elementos pertencentes ao PESET, aplicada em sala de aula no início da pesquisa, é reaplicada neste ponto de interpretação, a fim de analisar o que foi observado pelos alunos durante o percurso. 


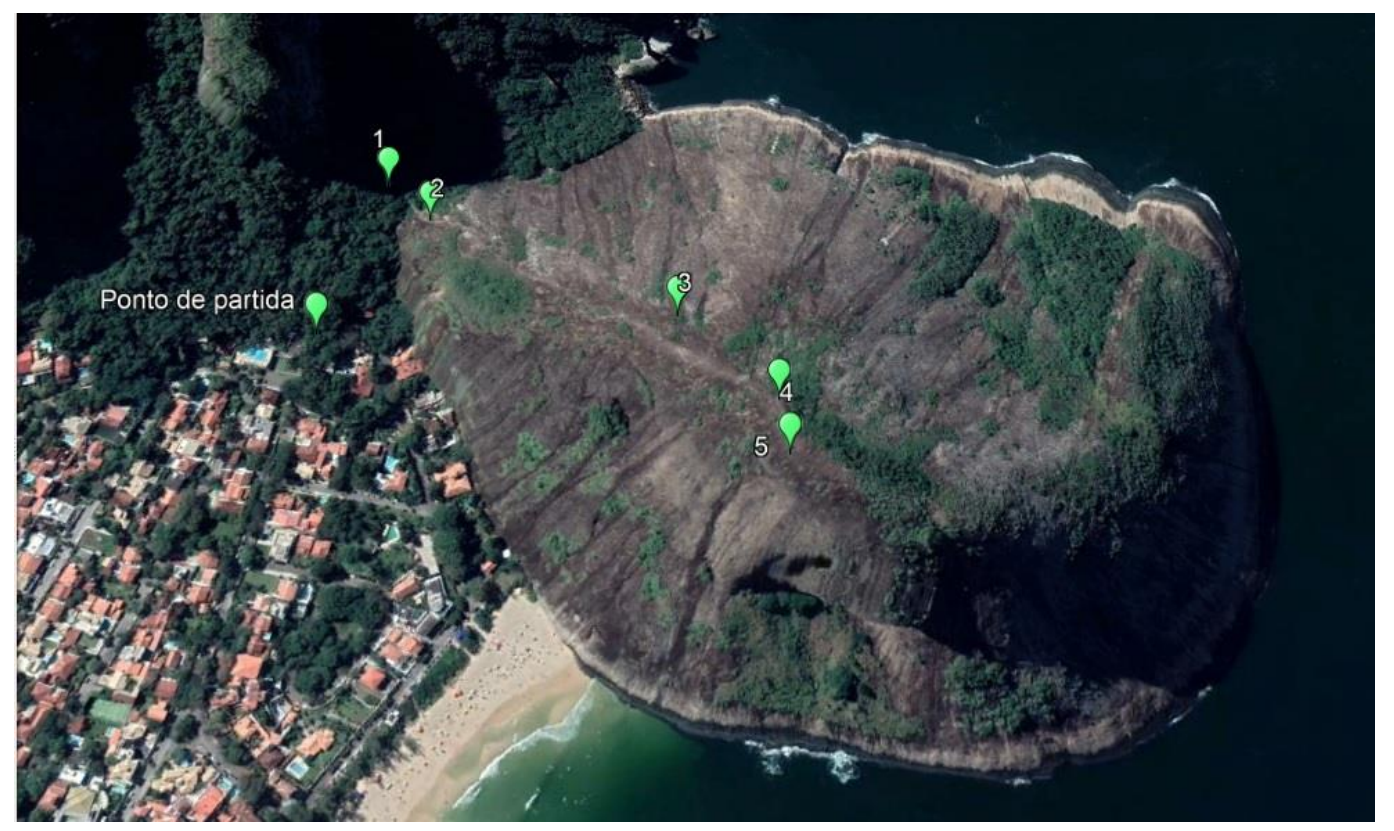

Figura 5: Pontos da Trilha Interpretativa do Costão de Itacoatiara. Fonte: Google Earth, 2019.

Figure 5: Points of the Itacoatiara Coast Interpretive Trail. Source: Google Earth, 2019

\section{Considerações Finais}

O trabalho objetiva a elaboração de um protocolo de Trilhas Interpretativas, para aplicação da ferramenta em diversas unidades de conservação e para diferentes públicos-alvo, com foco em estudantes do ensino fundamental, médio e superior. A elaboração das trilhas interpretativas junto a uma proposta pedagógica permite que se possa avaliar sua inserção em sala de aula e sua aceitação como estratégia didática por professores e alunos.

Todos os pontos de interpretação foram desenvolvidos a partir de observações em conjunto com os alunos, a fim de incentivar a postura consciente em unidades de conservação, integrar a escola a uma prática didática em ambiente natural e aproximar sociedade do meio ambiente em seu entorno. A implementação do protocolo de trilhas interpretativas corrobora com os objetivos educativos do PESET, estabelecido em seu plano de manejo.

A principal vantagem da elaboração de trilhas interpretativas junto a uma proposta pedagógica está justamente na possibilidade de estar inserido na rotina escolar dos alunos e professores, podendo observar de forma mais direta os impactos, positivos e negativos, que a atividade exerce nos atores evolvidos. As dificuldades e facilidades de se trabalhar junto a um cronograma escolar são latentes em todas as fases da pesquisa. Nesse sentido, como desvantagem, podese citar o adiamento de algumas saídas de campo, devido a condições climáticas desfavoráveis para subida ao Costão. Destaca-se, por fim, que estes resultados se configuram como dados parciais da Dissertação da autora no Programa de Pós Graduação em Ecoturismo e Conservação, que segue para conclusão das pesquisas ao final de 2019. 


\section{Referências}

ANDRADE, W.J. e Colaboradores. Manejo de Trilhas: um manual para gestores. São Paulo, n. 35, p. 1-74, 2008.

BARROS, A.A.M.; SEONNE, C.A. A problemática da conservação do Parque Estadual da Serra da Tiririca, Niterói / Maricá, RJ, Brasil. In: VALLEJO, L.R.; SILVA M.T.C. (eds) Os (des)caminhos do estado do Rio de Janeiro rumo ao século XXI. Instituto de Geociências da UFF, Niterói, p.114-124, 1999.

BARROS, A.A.M. Análise florística e estrutural do Parque Estadual da Serra da Tiririca, Niterói e Maricá, Rio de Janeiro, Brasil. Tese de Doutorado. Programa de Pós-Graduação em Botânica, Instituto de Pesquisas Jardim Botânico do Rio de Janeiro, Rio de Janeiro, 213 p, 2008.

BOTERF, L. G. Propostas e reflexões metodológicas. In: BRANDÃO, R. C. Repensando a pesquisa participante. 3르 Ed. Editora brasilienses,1987.

BRASIL. Lei 9985, de 18 de julho de 2000. Regulamenta o art. 225, § 10, incisos I, II, III e VII da Constituição Federal, institui o Sistema Nacional de Unidades de Conservação da Natureza e dá outras providências, 2000.

CANTO-SILVA, C.R.; SILVA, J.S. Panorama da visitação e da condução de visitantes em Parques brasileiros. Revista Brasileira de Pesquisa em Turismo. São Paulo, 2017, pp. 347-364.

COVA, B.F. G.; PIMENTEL, D.S. Mapeamento das trilhas do Parque Estadual da Serra da Tiririca (RJ): Planejamento para a Gestão do Uso Público. Revista Eletrônica Uso Público em Unidades de Conservação, Vol 1, no 1, 2013, Niterói/RJ.

DINIZ, F.K.B. (2016). Diagnóstico da Visitação no Costão de Itacoatiara, Parque Estadual da Serra da Tiririca, Niterói, RJ, Brasil. Dissertação de Mestrado. Programa de Pós-Graduação em Biologia Marinha e Ambientes Costeiros. Departamento de Biologia Marinha,Instituto de Biologia.Universidade Federal Fluminense, 2016.

EISENLOHR. P. V. e Colaboradores. Trilhas e seu papel ecológico: o que temos aprendido e quais as perspectivas para a restauração de ecossistemas. Hoehnea, v.40, n.3, 407-418, 1 tab, 2013.

IKEMOTO, S.; COSTA, V. C.; MORAES, M. G. Avaliação do potencial interpretativo da trilha do Jequitibá, Parque Estadual dos Três Picos, Rio de Janeiro. Sociedade e Natureza (Online), Uberlândia, v. 21, n. 3, 2009.

INEA. PLANO DE MANEJO. PARQUE ESTADUAL DA SERRA DATIRIRICA. Rio de Janeiro, 2015. Disponível em <http://www.femeri.org/wp-content/uploads/Plano-demanejo-do-Parque-Estadual-da-Serra-da-Tiririca-PESET.pdf > Acesso em 30/06/18.

LAYRARGUES, P.P.; LIMA, G.F.C. Mapeando as macrotendências políticopedagógicas da educação ambiental contemporânea no Brasil. Anais do ENCONTRO DE PESQUISA EM EDUCAÇÃO AMBIENTAL, 6., 2011. Ribeirão Preto.

LIMA, F.C.G. Educação Ambiental no Brasil. Formação, identidades e desafios. São Paulo: Papirus Editora, 2011.

LOUREIRO, C.; COSSÍO, M. Um olhar sobre a Educação Ambiental nas escolas: considerações iniciais sobre os resultados do projeto "O que fazem as escolas. In: 
Vamos Cuidar do Brasil: Conceitos e Práticas em Educação Ambiental na Escola. MINISTÉRIO DA EDUCAÇÃO. Brasília, 2007.

\section{MAGRO, T. C.; FREIXÊDAS, V. M. Trilhas: como facilitar a seleção de pontos} interpretativos. Circular Técnica IPEF, 1988.

MMA. Diretrizes para visitação em Unidades de Conservação. Série Áreas Protegidas, 3aㅡ Edição. Brasília. 2006, Disponível em: <http://www.mma.gov.br/ estruturas/ascom boletins/ arquivos/livro.pdf>. Acesso em 24/02/2019.

PEDRINI, A.G. Avaliação da qualidade do ecoturismo terrestre no brasil: estudo de caso com uma empresa atuante em trilhas, RJ. Anais do VI Congresso Nacional de Ecoturismo, Itatiaia, RJ, Brasil, 2007.

PIMENTEL, D.S. Os parques de papel e o papel social dos parques. Tese de Doutorado. Programa de Pós-Graduação em Recursos Florestais. Escola Superior de Agricultura Luiz de Queiroz, Piracicaba, Universidade de São Paulo, 2008, 254p.

PIMENTEL, D.S.; BARCELLOS, M.M. MEIRELES, C.P.; OLIVEIRA, M.L.; SANTOS, V.P. Trilhas Interpretativas como Estratégia de Educação Ambiental em Unidades de Conservação. In: SANTORI R.T.; SANTOS M.C.F.; SANTOS M.G. (Orgs). Da célula ao ambiente: propostas para o ensino de Ciências e Biologia, 2017.

PIRES, P.S.; RUGINE, V.M.T. (2018). Reconhecimento do Uso Público nos Parques Estaduais no Brasil com ênfase na visitação turística. Revista Brasileira de Ecoturismo, São Paulo, v.11, n.1, pp.61-80.

RIO DE JANEIRO (estado) Lei no 1.901, de 29 de novembro de 1991. Dispõe sobre a criação do Parque Estadual da Serra da Tiririca e dá outras providências,1991.

VASCONCELLOS, J.M.O. Educação e interpretação ambiental em unidades de conservação. Cadernos de conservação. Fundação 0 Boticário de Proteção à Natureza. Curitiba, n.4, p.86, 2006.

VALLEJO, L.R. Políticas públicas e conservação ambiental: territorialidade em conflitos nos Parques Estaduais da llha Grande, da Serra da Tiririca e do desengano (RJ). Tese de Doutorado. Pós-Graduação em Geociências, Universidade Federal Fluminense, Niterói, 228 p., 2005.

VALLEJO, L.R. Uso Público em Áreas Protegidas: Atores, Impactos e Diretrizes de Planejamento e Gestão. Uso Público em Unidades de Conservação, Niterói/RJ, v.1, n.1, pp.13-26, 2013.

TILDEN, F. Interpreting our Heritage. Chapel Hill: University of North Carolina Press. 3. 191 p, 1977. 
Priscila Gonçalves Costa: Universidade Federal do Estado do Rio de Janeiro e Universidade do Estado do Rio de Janeiro, Rio de Janeiro, RJ, Brasil

E-mail: priscilag.costa@yahoo.com.br

Link para o currículo Lattes: http://lattes.cnpq.br/2535008425233428

Douglas de Souza Pimentel: Universidade do Estado do Rio de Janeiro e Universidade Federal Fluminense, Rio de Janeiro, RJ, Brasil

E-mail: douglas.geia@gmail.com

Link para o currículo Lattes: http://lattes.cnpq.br/9374128914372886

Alba Valéria Santos Simon: Universidade Federal do Estado do Rio de Janeiro, Rio de Janeiro, RJ, Brasil

E-mail: albasimon7@gmail.com

Link para o currículo Lattes: http://lattes.cnpq.br/8823587354409981

Amaro Rodrigo Correia: Secretaria de Estado de Educação do Rio de Janeiro, Rio de Janeiro, RJ, Brasil

E-mail: prof.rd.correia@gmail.com

Link para o currículo Lattes: http://lattes.cnpq.br/7356242076510426

Data de submissão: 19 de março de 2019

Data de recebimento de correções: 26 de março de 2019

Data do aceite: 26 de março de 2019

Avaliado anonimamente 